\title{
معوقات تقويم مجالات التدريب والتنمية المهنية المستدامة وأثر التدريب والمتابعة
}

\author{
الباحثة /أميزة محمد محمود عبدالله

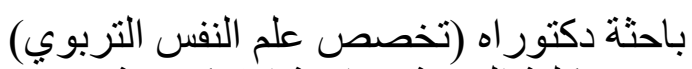 \\ كلية التربية- جامعة الإسكندرية النية
}

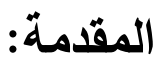

ان الاعداد لمهنة التعليم في هذا العصر أصبح عملا لاينتهي باعداد الطالب في كليات التربية واعداد المعلمين، فإن فترات التدريب العملي لاتكتفي بوضع المعلم في مكانته المهنية الصحيحة و لكي تكتمل أطراف هذه العملية لابد من التدريب أثناء الخدمة للإزتقاء بمستوى آداء المعلم لتحقيق اهداف عملية الإعداد قبل وأثناء الخدمة.

ولقد بينت معظم الدراسات التي أجريت حول برامج التدريب أثناء الخدمة أن هناك تأثثرا

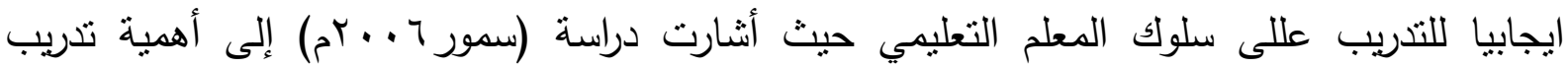
المعلمين من خلال برنامج المدرسة في وحدة التدريب وأوصت الدراسة ببناء برامج تربوية حسب إحتباج المعلمين، والعمل على تحسن مدخلات كليات التربية وانشاء مراكز متخصصة لتطوير اعداد المعلم وكذلك الاستفادة من أساتذة كلات التربية في هذا المجال من أجل لاالحفاظ عللى التتمية المهنية

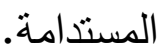

وقد أصبح الإنماء المهني أكثر ضرورة من أجل توفير الخدمة التربوية اللازمة للمعلم، والتي تتضمن تزويده بمواد التجدد في المجالات العلمية التربوية، وبالمستجدات في اساليب وتقنتيات التعليم والتعلم وتدريبه عليها واجراء البحوث الإجرائية، و استبعاب كل ماهو جديد في النمو المهني من تطورات تربوية وعلمية ..........

ومن هنا ظهرت الفكرة لدى الباحثة لاكتثاف معوقات تقويم مجالات التثريب والتتمية الدهنية المستدامة للمعلمين وأيضا كيفية التغلب على تلك المعوقات من خلال الدراسة.

\section{مشكلة البحث}

إن عمليات النقويم والمتابعة في التدريب يجب أن نتشمل جميع أبعاد ومجالات عمليات التدريب و التتمية المهنية المستدامة للمعلم وبشكل أساسي؛ ولكن معوقات تقويم مجالات التدريب والتنمية

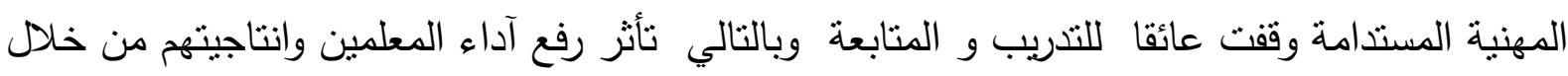
تطوير كفاياتهم التعليمية بجانبيها المعرفي والآدائي. 
فيحاول البحث المساهمة في التخفيف من المعوقات التي تواجه تقويم مجالات التنريب والتتمية المهنيه المستدامه وذلك من خلا الأسئلة التالية:

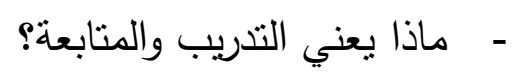

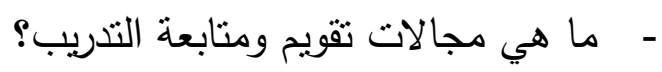

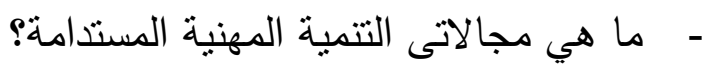

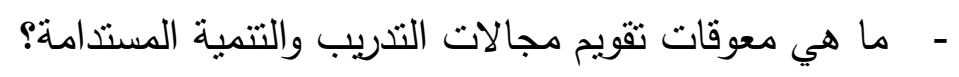

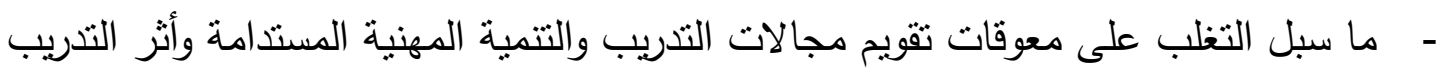

$$
\text { والمتابعة؟ مانج }
$$

\section{أهداف البحث}

تتمنك أهداف البحث الحالي في التالي:

( ) نوضيح أسس وقواعد تقويم البرامج التدريبية.

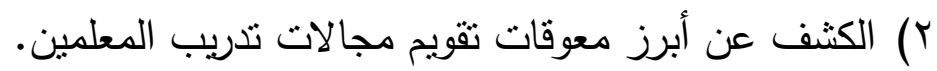
؟) التعرف على سبل التغلب على معوقات نقويم تدريب المعلمين ؛) نوضيح أثز التنريب والمتابعة في آداء المعلمين. أهمية البحث

تجلت أهمية البحث الحالي واضحة فيما يلي

$$
\text { ( ) تعميق تقويم مجالات تدريب المعلمين. }
$$

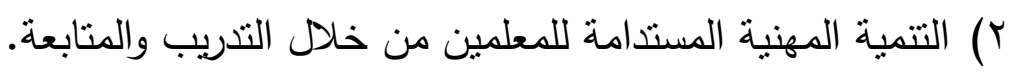

r) تفعيل التغلب على معوقات تقويم مجالات تدريب المعلمين.

لقد اختلف الكتاب والباحثون حول تعريف التدريب عموما والتدريب الإداري خاصة، إالا أن تعريفاتهم متفقة على الركائز الأساسية لعملية التدريب، في أنها تؤدي إللى التغيير أو النطوير الذي التي

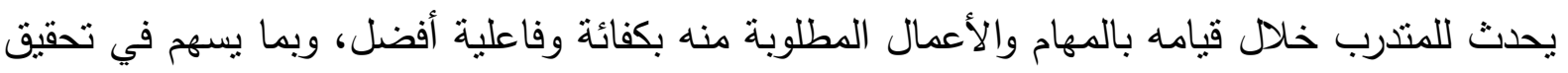
أهدافه وأهداف المنظمة والمجتمع؛" وقد عرفه الهيتي على أنه: جهود إدارية وتتظيمية مرتبطة بحالة

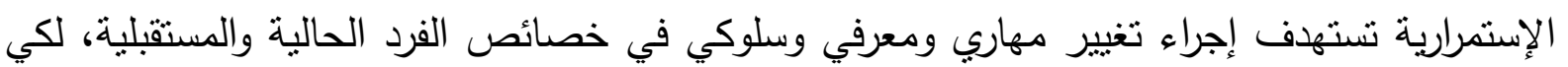
يتمكن من الإيفاء بمنطلبات عمله ويطور آدائه العملي والسلوكي بشكل أفضل.

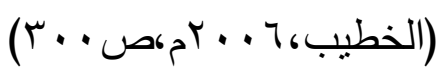


وأثر التدريب والمتابعة (أميرة محمد محمود عبدالله)

وتعرفه وزارة التربية والتعليم بأنه عملية إكساب مجموعة من المعارف والمهارات والإتجاهات الى فرد أو مجموعة أفراد، والتي بها يستطيع هذا الفرد أو هذه المجموعة القيام بعمل مالم يكن في باله

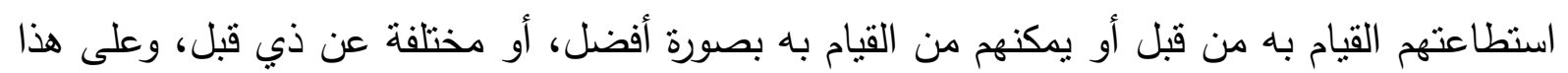

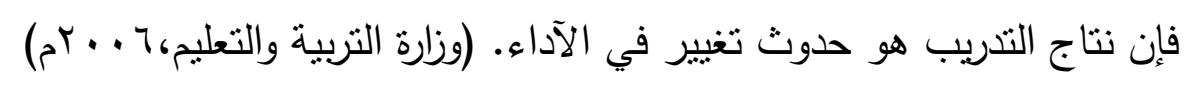

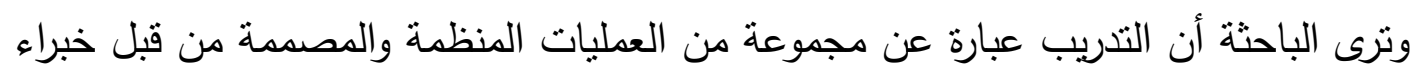

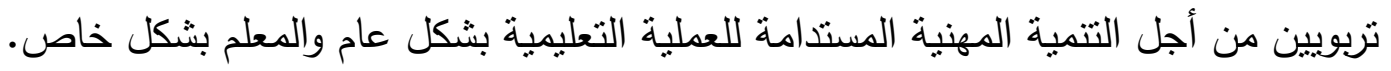

\section{مجالات تقويم ومتابعة التدريب:}

إن عمليات التقويم والمتابعة في التدريب يجب أن تشمل جميع أبعاد ومجالات عمليات التدريب وبشكل أساسي لابد وأن تغطي المجالات التالية:

ومتابعة () تقويم

وتتم هذه العملية عبر ثلاث خطوات لقياس كفاءة وفاعلية البرنامج وهي بالترتيب:

- قبل التففذ: للتأكد من دقة وسلامة خطة البرنامج التدريبي ومدى قدرتها على تحقيق أهدافها.

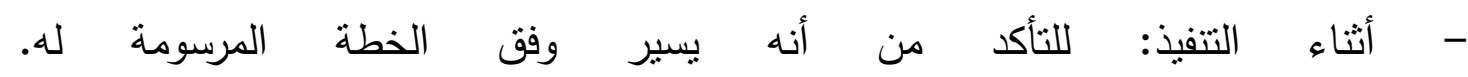
-بعد التنفيذ: للتأكد من تحقيقه للأهداف ومدى مساهمته في تلبية الاحتياجات التثريبية.

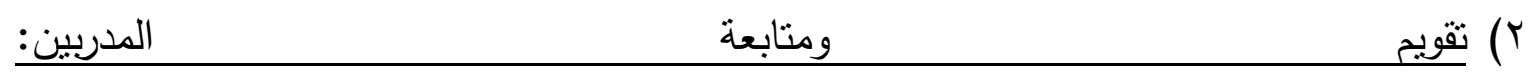

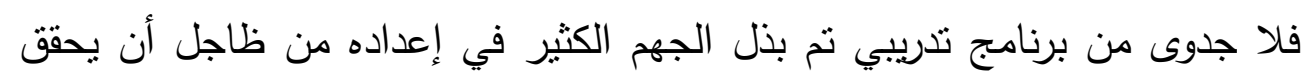

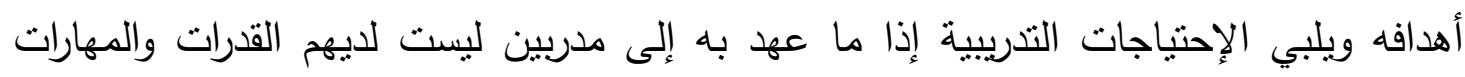
والكفايات التخصصية والخبرة .

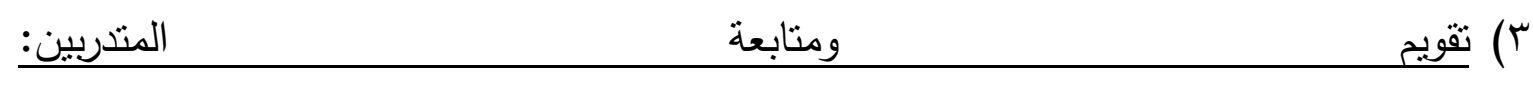

المتدربون هم الجمهور المستهدف في أي برنامج تدريبي، فالبيئة التدريبية والأجهزة

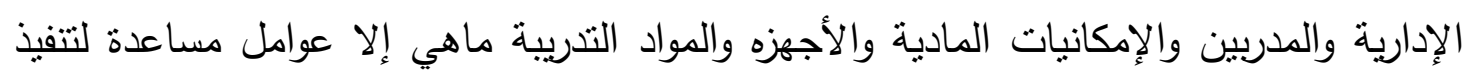

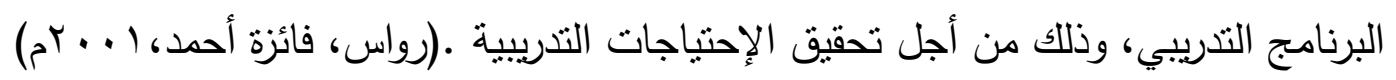

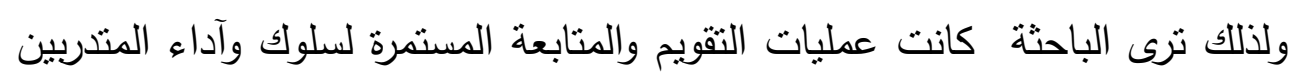
أثناء فترة التدريب وبعد عودتهم إلى مواقع عمهم هي المعيار الصحيح الذي يينى عليه ددى نجاح التهاح

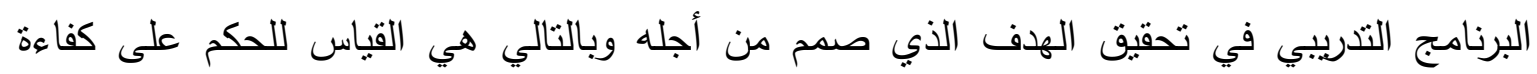
وفاعلية الرنامج التدريبي. 
وأثر التدريب والمتابعة (أميرة محمد محمود عبدالله)

حيث تعتبر التتمية المهنيه المستدامة عنصرا مستمرا ومتجددا ومواكبا للمستجدات، وأيضا تعود مرجعيته للدوافع الذاتيه من قبل المعلمين وتقاس بناءا عللى مخرجات تعلم الطلبة لذالك تعددت

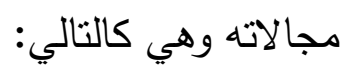
ا - مجال التطوير والتجديد والتحديث في المجال الأكاديمي التخصصي. r - مجال العلاقات الإنسانية والإرشاد والتوجيه الطلابي والتفاعل والتواصل في المواقف التعليمية. r- مجال البحث العلمي والأكاديمي. ع - مجال التتمية والتطوبر الذاتي والتقييم الذاتي. 0- مجال توظيف تقنيات التعليم والاتصالات في المجال التعليمي. ج- مجال الالتزام بأخلاقيات المهنية وتعديل السلوك والاتجاهات. -V

http://www.ibrahimrashidacademy.net

ومما سبق ترى الباحثة أن عمليات تقويم مجالات التذريب والتتمية المهنية المستدامة تتطلب بشكل رئيسي تكاتف جميع جهات المجال التعليمي لضمان نجاح تطور العملية التعليمية، واتحاد المؤسسات مع الأفراد للوصول لمستوى مقبول من تعزيز المعرفة المهنية والوظيفية لدى الأفراد من خلا صقل مهاراتهم وقدراتهم بما يتماشى مع أهداف المنشآت التعليمية وعملها لتجز بالثكل المطلوب. ولكن التدريب الحالي للمعلمين أيا كانت الجهة التربوية التي تعقده لايؤدي المطلوب ولا يحقق لنتائج المرجوة من عملية التذريب للمعلم لأن طريقته من وجهة نظرنا ممله وروتينية ينبغي اعادة النظر فيها وترتيب عملية التدريب لنتمكن بعد ذلك من تمهين التعليم ونحن مطمئنون على المعلم.

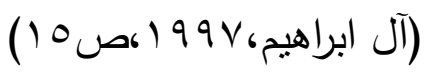

\section{معوقات تقويم مجالات التدريب والتنمية المهنية المستدامة:}

فعملية تقوبم التدريب والتتمية المهنية المستدامة تواجه أثناء تطبيقها الكثير من المعوقات التي تؤدي بدورها لجعلها عملية صعبة التقيذ، مما يؤثز سلبا عللى مجالات التذريب والتتمية المهنية المستدامة، فيمنعها من التطور ، ومن هذه المعوقات: ( ) عدم توفر أدوات وأساليب تقويم مقننة وسهلة النطبيق. r) حصر التقويم على الإختبارات. r) قلة الإمكانيات المادية التي تساعد على استخدام أكثر من وسيلة للتقويم. 
ع) قلة المختصين في مجال النقويم إلى جانب قلة كفاءة الموجودين. 0) لا يوجد وعي لاى المندربين والددربين بأهية تقويم برامج التدريب. 4) عدم نوفر معلومات وإحصائيات دقيقة تساعد على تقويم البرامج الندريبية

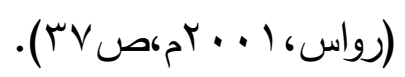

V عدم التخطيط المسبق لعملية تقويم البرامج تؤدي إلى إعاقة العملية التقويمية. ^) عدم استخدام التقويم التنبعي في تحديد آثار التدريب الطويلة في مواقع العمل. 9) عدم موضوعية بعض الاختبارات المستخدمة في التقويم. • ( ) لا يستخدم أدوات متتوعة لجمع المعلومات في تقويم البرامج التدريبية.

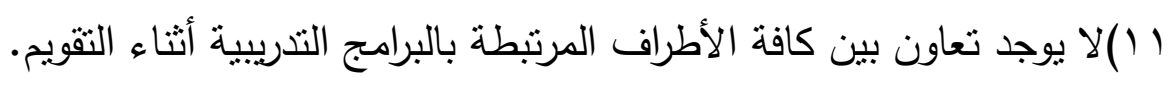

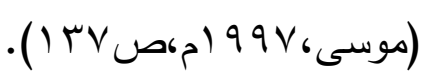

ومن هنا ترى الباحثة بيان علاقة التقويم بالتدريب داخل المدرسة وأهميتها لضمان برامج ناجحة،

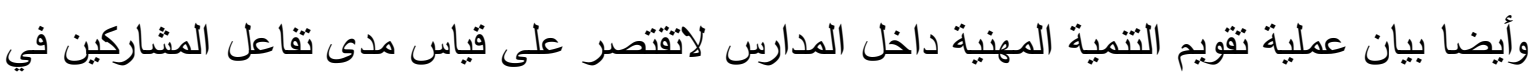

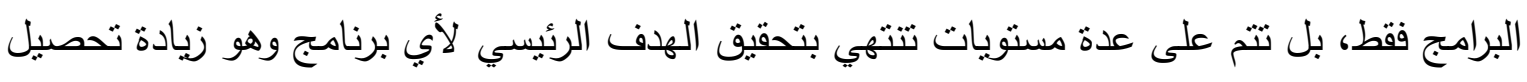
الطالب.

\section{كيف يمكنتا التظلب على معوقات تقويم مجالات التدريب والتتمية المهنية المستدامة؟}

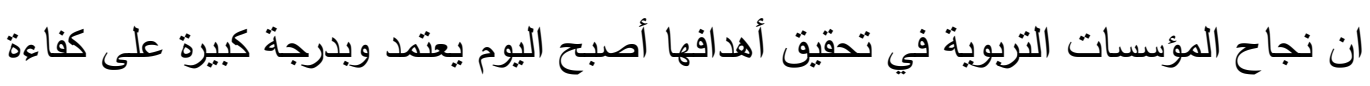

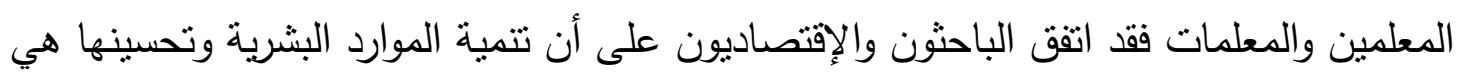

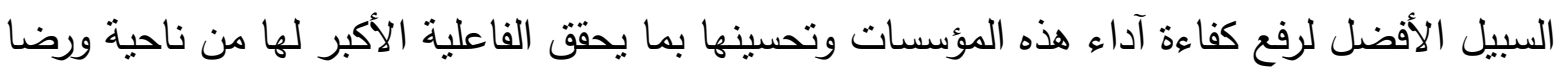
العاملين من ناحية ورضا العاملين بها من ناحية أخرى.

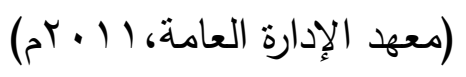

لذللك يمكننا التغلب على تلك المعوقات من وجهة نظر الباحثة كما يلي: ( ) توفير الإمكانيات المادية لدى المؤسسات التربوية وخاصة القائمة على التتمية المهنية. r اعداد كوادر بشرية متخصصة في مجالات التقويم والقياس داخل المؤسسات.

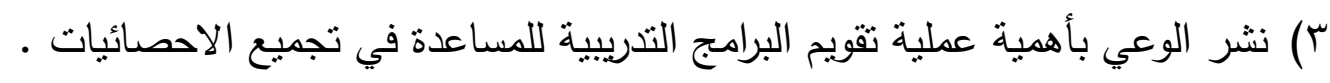

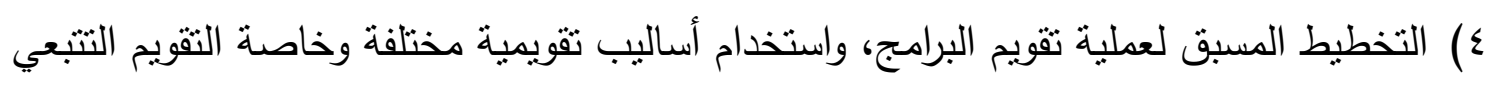
لإكتشاف نقاط الضعف أولا بأول. 0) استخدام أساليب موضوعية ومتاحة للاستخدام في عمليات التقويم حيث تكون مطابقة لأرض الواقع. 
معوقات تقويم مجالات التدريب والتنمية المهنية المستدامة

المجلة العربية للقياس و التقويم

وأثر التدريب وإلمتابعة (أميرة محمد محمود عبدالله)

ج) ويأتي الدور الأقوى وهو تعاون كافة الأطراف القائمة على التتمية المهنية المستدامة لتحقيق الأهداف الموضوعة في التخطيط المسبق.

\section{توصيات البحث:}

في ضوءالنتائج التي توصل اليها البحث الحالي توصي الباحثة بالآتي:

- توفير الوقت اللازم من خلال الادارات المدرسية والتكاليف اللازمه للمعلمين لممارسة أنشطة

التتمية المهنية.

- وجود لجنة مخصصة لتقويم التدريب والتتمية المهنية المستدامة داخل المدارس.

- استغلال أوقات تقابل المعلمين مع بعضهم أو بينهم وبين الإدارات التعليمية في التخطيط للنمو

$$
\text { المهني أكثر من استخدامه في الأغراض الإدارية والمعرفية. }
$$

- اعداد واختيار مديري المؤسسات التعليمية بحيث يكونوا أفراد تتسم بالمرونة والوعي بأهمية دورها

في تذليل الصعاب التي تواجه تقويم التتمية المهنية داخل المدرسة. 


\section{المراجع}

آل ابر اهيم، ابر اهيم عبدالرزاق(9 9 (1) نحو خطوات جديدة لتمهين التعليم، مجلة التربية،

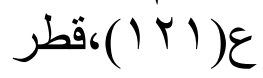
الخطيب، رداح،الخطيب،أحمد(T + . rم) التذريب الفعال، عالم المكتب الحديث،إربدالأردن.

العامة لتعليم البنات في مكة وجدة من وجهة نظر المدربات والتذربين ، رسالة ماجستير ، ردة جامعة أم القرى، مكة المكرمة. رواس، فائزة أحمد( ( . . rم) ، تقويم برامج مركز التقويم التدريب التربوي بالرئاسة.

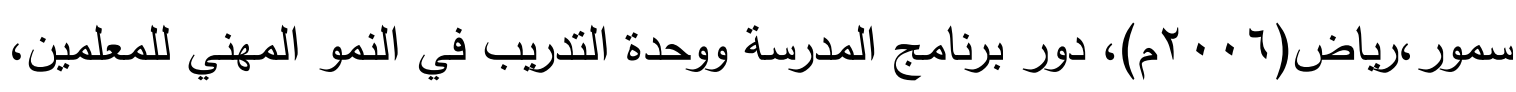
مجلة الجامعة الإسلامية، المجلد الرابع عشر ، العدد الثاني، غزة، فلسطين.

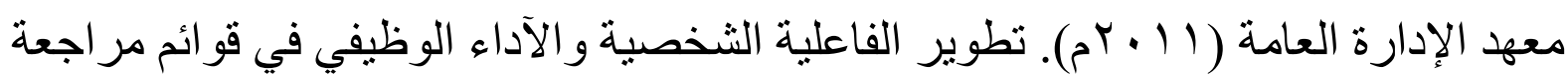

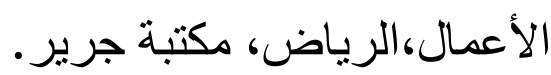

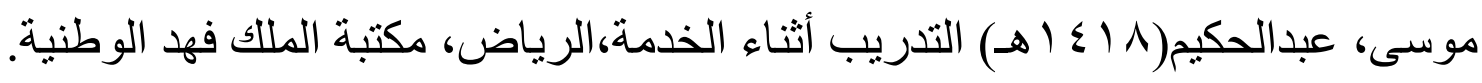

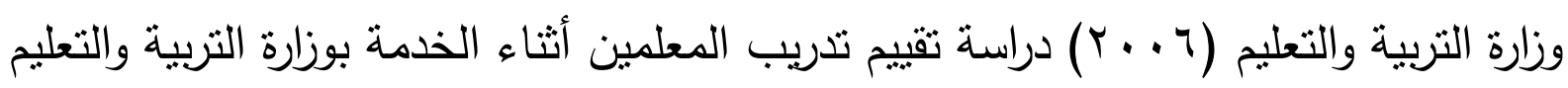
العالي الفلسطينية بالتعاون مع المجلس الثقافي البريطاني وتمويل البنك الدولي. 